\title{
THE PREVALENCE OF THYROID DYSFUNCTION IN ELDERLY CARDIOLOGY PATIENTS WITH MILD EXCESSIVE IODINE INTAKE IN THE URBAN AREA OF SÃO PAULO
}

\author{
Glaucia C. Duarte, ${ }^{\mathrm{I}}$ Eduardo K. Tomimori, ${ }^{\mathrm{I}}$ Rosalinda Y. A. Camargo, ${ }^{\mathrm{I}}$ Ileana \\ G.S. Rubio, ${ }^{\mathrm{I}}$ Mauricio Wajngarten, ${ }^{\mathrm{II}}$ Amanda G. Rodrigues, ${ }^{\text {II }}$ Meyer Knobel, ${ }^{\mathrm{I}}$ \\ Geraldo Medeiros-Neto ${ }^{\mathrm{I}}$
}

doi: 10.1590/S1807-59322009000200011

Duarte GC, Tomimori EK, Camargo RYA, Rubio IGS, Wajngarten M, Rodrigues AG, Knobel M, Medeiros-Neto G. The prevalence of thyroid dysfunction in elderly cardiology patients with mild excessive iodine intake in the urban area of São Paulo. Clinics. 2009;64:135-42.

OBJECTIVES: To evaluate the prevalence of thyroid dysfunction in elderly cardiac patients in an outpatient setting.

SUBJECTS AND METHODS: A total of 399 consecutive patients (268 women, age range 60-92 years) who were followed at Heart Institute were evaluated for thyroid dysfunction with serum free T4, TSH, anti-Peroxidase antibodies, urinary iodine excretion measurements and thyroid ultrasound.

RESULTS: Hyperthyroidism (overt and subclinical) was present in 29 patients (6.5\%), whereas hypothyroidism (overt and subclinical) was found in 32 individuals (8.1\%). Cysts were detected in 11 patients (2.8\%), single nodules were detected in $102(25.6 \%)$, and multinodular goiters were detected in $34(8.5 \%)$. Hashimoto's thyroiditis was present in $16.8 \%$ patients, most of whom were women $(83.6 \%)$. The serum TSH increased with age and was significantly higher $(\mathrm{p}=<0.01)$ in patients, compared to the normal control group. No significant differences in serum TSH and free T4 values were observed when patients with atrial fibrillation (AF) where compared with those without arrhythmia. The median urinary iodine levels were $210 \mu \mathrm{g} / \mathrm{L}(40-856 \mu \mathrm{g} / \mathrm{L})$, and iodine levels were higher in men than in women $(\mathrm{p}<0.01)$. Excessive iodine intake (urinary iodine $>300 \mu \mathrm{g} / \mathrm{L}$ ) was observed in one-third of patients $(30.8 \%)$.

CONCLUSIONS: Elderly patients have a higher prevalence of both hypo- and hyperthyroidism as well as thyroid nodules when compared with the general population. About one-third of the older patients had elevated urinary secretion of iodine and a higher prevalence of chronic Hashimoto's thyroiditis. It is recommended that ultrasonographic studies, tests for thyroid function and autoimmunity should be evaluated in elderly patients.

KEYWORDS: Iodine intake; Thyroid dysfunction; Cardiologic patients; Elderly patients; Urinary iodine.

\section{INTRODUCTION}

Thyroid diseases are common clinical problems associated with aging. ${ }^{1-5}$ In the elderly, a reduction in the activity of the

\footnotetext{
I Thyroid Unit, Division of Endocrinology, Hospital das Clinicas, University of Sao Paulo Medical School, Sao Paulo, Brazil

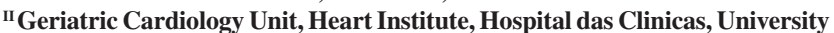
of Sao Paulo Medical School, Sao Paulo, Brazil

Email: medneto@uol.com.br

Tel.: $55113064-6835$

Received for publication on August 08, 2008

Accepted for publication on October 30, 2008
}

hypothalamus-hypophysis-thyroid axis is expected and is associated with an inadequate response of pituitary hormone release after provocative tests. The thyroid gland undergoes anatomical and physiological adaptations in association with age (changes in weight, iodine uptake and hormone synthesis), which provide evidence of a reduction in thyroid function. ${ }^{4}$ In humans, there is also an age-dependent increase in thyroid volume and nodularity. The degree of this increase depends upon several factors, including iodine intake, and its detection depends on the methods (clinical, echographic or pathological) employed for evaluation..$^{5}$ It is also relevant that the curve of the relationship between the iodine intake level 
and the occurrence of thyroid diseases within a population is U-shaped, with an increase in risk with both low and high iodine intake levels. Thus, interpreting data on the prevalence of thyroid disease in a specific area must take into account the influence of the iodine intake in that region. ${ }^{6}$ A study conducted in Denmark showed that aging is accompanied by a high prevalence of goiter, mainly in areas of low iodine intake ${ }^{7}$. Also, a recent survey showed that the prevalence of goiter in the elderly population reaches figures as high as $74 \%$ in patients aged $55-75$ years and $54 \%$ in patients aged 76-84 years, with a prevalence of nodular goiter of $25 \%$ and $21 \%$, respectively. ${ }^{8}$ Another study comprised of 634 endocrinology outpatients with goiter (age range 55-91, 544 women) indicated that nontoxic and toxic multinodular goiter were the predominant thyroid abnormalities. Furthermore, dietary iodine may increase the risk of chronic autoimmune thyroiditis and for hyperthyroidism in the elderly. ${ }^{10}$

Gender also seems to be an important determinant. For example, hypothyroidism is far more common among elderly women than men, particularly in the presence of thyroid antibodies. ${ }^{5,10}$ However, evaluating thyroid function in the elderly is complicated by an increased prevalence of nonthyroidal illness and autoimmune subclinical hypothyroidism. ${ }^{11}$

We have previously demonstrated an elevated urinary iodine concentration $(>300 \mu \mathrm{g} / \mathrm{L})$ in $53 \%$ of 844 schoolchildren in São Paulo. This observation led us to infer that the population of this large Brazilian state could be exposed to a mildly excessive daily iodine intake. ${ }^{12} \mathrm{We}$ assumed that the adult population, especially individuals aged 60 years and older, could also be ingesting high levels of iodine.

The purpose of this cross-sectional study was to evaluate the thyroid parameters of function, autoimmunity, ultrasonographic aspects and size in older subjects from an urban area in São Paulo with a mild iodine excess.

\section{SUBJECTS AND METHODS}

\section{Patients}

Subjects were recruited from a random sample of outpatients attending the cardiology follow-up clinic at the Geriatric Cardiology Unit, Heart Institute, Hospital das Clinicas, University of Sao Paulo Medical School, in São Paulo, Brazil.

Participants were aged 60 years and older and had no history of thyroid or liver disease, thyroid surgery, radioactive iodine therapy, had not been evaluated with radiologic tests using contrast media, were not on iodinecontaining vitamin/mineral preparations, antithyroid drugs or thyroid hormone. A detailed clinical history, review of previous case record, and a clinical examination were performed for each participant.

Enrollment included 400 consecutive patients (268 women). One patient was excluded due to non-compliance with the study protocol. The final study population was comprised of 399 patients with a mean age of $73.3 \pm 7.5$ years (range 60-92 years, median 73 years). Among the participants, 46 had atrial fibrillation (AF). The population was subdivided into groups according to the following age ranges: $60-70$ years $(n=138), 71-80$ years $(n=175)$, and 81 92 years $(n=75)$.

A control group of 320 normal subjects (age range 18-60 years, 213 women) from the metropolitan area of São Paulo, Brazil was selected. Individuals in this group had a normal thyroid upon physical examination and ultrasound, negative thyroid peroxidase auto-antibodies (TPOAb), and no history of either past or present thyroid disease or treatment with thyroid hormone.

The criteria for a normal thyroid ultrasound were a homogeneous echogenic pattern throughout the gland, absence of nodules and cysts, and an absence of diffuse or heterogeneous abnormalities. Normal levels of urinary iodine excretion were between 100 and $299 \mu \mathrm{g} / \mathrm{L}$.

In this reference cohort, serum thyroid-stimulating hormone (TSH) levels ranged from 0.6 to $3.7 \mathrm{mU} / \mathrm{L}$ with a mean \pm SD of $1.8 \pm 0.8 \mathrm{mU} / \mathrm{L}$, and serum free T4 (FT4) ranged from 0.87 to $1.6 \mathrm{ng} / \mathrm{dL}$ (mean $\pm \mathrm{SD} 1.16 \pm 0.2 \mathrm{ng} /$ dL). Thyroid volume ranged from 6 to $14.2 \mathrm{~mL}$ in women and 7 to $14.9 \mathrm{~mL}$ in men.

\section{Design}

Patients were asked about their present and past history of thyroid disease; presence of neck enlargement over the past year; use of medications; local symptoms, such as dyspnea, dysphagia, dysphonia, pain or discomfort; and general manifestations, such as weight or appetite loss, depression, apathy or irritability, palpitations, and muscle weakness. The majority of these patients had hypertension, mild left ventricular dysfunction, and chronic fatigue, but otherwise was in relatively good health. Standard clinical, analytical and morphological (ultrasonography) procedures were used for etiological diagnoses. Serum TSH, FT4 and TPOAb were obtained in all patients. Nonfasting spot urine and household salt samples were collected for iodine determination.

The study was approved by Hospital das Clínicas Research Ethics Committee. All participants agreed to participate in the study and signed an informed consent in accordance with institutional requirements. 


\section{METHODS}

Fasting blood samples were drawn and stored at $-20^{\circ} \mathrm{C}$ for a variety of assessments, including thyroid tests.

Thyroid function tests: TSH (reference range $0.5-4.0 \mu \mathrm{U} /$ $\mathrm{mL}$, functional detection limit $0.03 \mu \mathrm{U} / \mathrm{mL}$ ), FT4 (reference range $0.9-1.7 \mathrm{ng} / \mathrm{dL}$ ), and TPOAb (reference range $<35$ $\mathrm{U} / \mathrm{mL}$ ) were measured by solid-phase fluorimmunoassays (AutoDELPHIA hTSH Ultra; AutoDELPHIA free thyroxine (FT4); and AutoDELPHIA TPOAb, PerkinElmer Life and Analytical Sciences, Wallac Oy, Finland).

Echographic studies: Thyroid ultrasonographic studies were conducted by the same investigators (GD and EKT) using a portable apparatus $(7.5 \mathrm{mHz}$ transducer; GE Medical Systems, USA). Thyroid volume was calculated according to the formula width $\mathrm{X}$ length $\mathrm{X}$ thickness $\mathrm{X} 0.524$ for each lobe and added to the isthmus volume. ${ }^{13}$ Goiter was diagnosed if the thyroid volume was above $18 \mathrm{~mL}$ for men or $16 \mathrm{~mL}$ for women, as previously reported ${ }^{13}$. Considering that the degree of hypoechogenicity is associated with the appearance of thyroid dysfunction in patients with thyroid autoimmunity, we analyzed the echogenic pattern (hyperechoic, isoechoic, hypoechoic) of the thyroid in comparison to the neck muscles. The results were expressed as follows: grade 1 (normal and hyperechoic), grade 2 (slightly hyperechoic), grade 3 (mildly hypoechoic), and grade 4 (extensively hypoechoic). ${ }^{14}$

Additional ultrasound structural focal abnormalities were described as cysts (circumscribed areas of greatly reduced or absent echogenicity), single nodules or multiple nodules.

\section{Urinary iodine excretion}

Urinary Iodine concentration was assayed using a modified Sandell-Kolthoff method ${ }^{15}$ in the nonfasting urine samples. Urine was collected between 8 and $12 \mathrm{PM}^{16}$ in Monovette plastic syringes, which do not interfere with iodine determination, and frozen at $-20^{\circ} \mathrm{C}$ within $30 \mathrm{~min}$ of collection. Concentration of iodine was expressed as $\mu \mathrm{g}$ of iodine per $\mathrm{L}$ of urine.

\section{Concentration of iodine in salt samples}

The current legal concentration of iodine in salt for human use is $20-60 \mathrm{mg}$ of iodine/kg of salt (National Agency for Sanitary Surveillance, March 2003). The iodine content in salt samples were assayed at the end of the study and presented as $\mathrm{mg}$ of iodine per $\mathrm{kg}$ of salt $(\mathrm{mg} \mathrm{I} / \mathrm{kg})$.

\section{Diagnostic criteria}

Thyroid dysfunction was defined according to the following laboratory reference values: overt hyperthyroidism ( TSH $<0.1 \mu \mathrm{U} / \mathrm{mL}$ and FT4 $>1.7 \mathrm{ng} / \mathrm{dL}$ ), subclinical hyperthyroidism (TSH $>0.4 \mu \mathrm{U} / \mathrm{mL}$ and FT4 $>1.7 \mathrm{ng} / \mathrm{dL}$ ), overt hypothyroidism (TSH $>4.0 \mu \mathrm{U} / \mathrm{mL}$ and FT4 $<0.7 \mathrm{ng} /$ $\mathrm{dL}$, and subclinical hypothyroidism (TSH $>4.0 \mu \mathrm{U} / \mathrm{mL}$ and FT4 $>0.7 \mathrm{ng} / \mathrm{dL}){ }^{7}$ Serum TSH levels between $0.1-0.5 \mu \mathrm{U} /$ $\mathrm{mL}$ were considered suppressed.

The diagnosis of autoimmune thyroid disease was defined by the following parameters: (1) a marked absence of echoes within the limits of the thyroid on ultrasound (grades 3 and 4, or marked hypoechogenicity) or the presence of an atrophic gland (volume smaller than $4 \mathrm{~mL}$ ) and (2) the presence of TPOAb $(>35 \mathrm{U} / \mathrm{mL})$ associated with echographic pattern of marked hypoechogenicity or thyroid atrophy.

\section{Statistical analysis}

Quantitative variables are presented as the means \pm standard deviation, and the qualitative variables are presented as proportions. The chi-square test was used to compare two group means for normally distributed data, except for TSH, FT4, thyroid volume, urinary iodine and TPOAb, in which non-parametric statistics were used with the Mann-Whitney test. The chi-square test was used to compare proportions between independent groups. The level of significance was set to 5\%. Statistical analysis was conducted using SAS 8.0 software (Statistical Analysis System, Cary, NC, USA) and Minitab version 14 (Minitab, Inc., State College, PA, USA).

\section{RESULTS}

\section{Prevalence of thyroid dysfunction}

Among the 399 subjects, three $(0.8 \%)$ had overt hyperthyroidism (two women, age range 66-79 years), and $26(6.5 \%)$ had subclinical hyperthyroidism (21 women, age range $60-85$ years).

Overt hypothyroidism was present in 17 individuals (4.3\%, 11 women, age range 61-91 years), whereas subclinical hypothyroidism was found in 15 patients $(8.1 \%$, 10 women, age range 70-86 years).

\section{Serum TSH}

The mean TSH value was $2.1 \pm 3.1 \mu \mathrm{U} / \mathrm{mL}$ (median 1.5 $\mu \mathrm{U} / \mathrm{mL}$, range $0.03-46.1 \mu \mathrm{U} / \mathrm{mL}$ ) (Table 1). TSH values were similar in men and women (mean $2.14 \pm 3.68 \mu \mathrm{U} /$ $\mathrm{mL}$ versus $1.83 \pm 1.39 \mu \mathrm{U} / \mathrm{mL}$, respectively, $\mathrm{p}=0.647)$. The 
Table 1 - Demographic aspects, thyroid laboratory tests, thyroid volume, and urinary iodine concentration in patients with and without atrial fibrillation

\begin{tabular}{|c|c|c|c|c|}
\hline & $\begin{array}{l}\text { Total Cohort } \\
(\mathrm{n}=399)\end{array}$ & $\begin{array}{l}\text { Patients with atrial } \\
\text { fibrillation }(\mathrm{n}=46)\end{array}$ & $\begin{array}{l}\text { Patients without atrial fibrilla- } \\
\text { tion }(\mathrm{n}=353)\end{array}$ & $\begin{array}{c}\text { Significance } \\
\mathrm{p}\end{array}$ \\
\hline \multicolumn{5}{|l|}{ Sex } \\
\hline Men & 268 & 15 & 116 & \multirow[t]{2}{*}{0.973} \\
\hline Women & 131 & 31 & 237 & \\
\hline \multicolumn{5}{|l|}{ Age, years } \\
\hline Mean \pm SD & $73.3 \pm 7.5$ & $76.6 \pm 6.3$ & $72.8 \pm 7.5$ & 0.001 \\
\hline \multicolumn{5}{|l|}{$\mathrm{TSH}(\mu \mathrm{U} / \mathrm{mL})$} \\
\hline Mean \pm SD & $2.1 \pm 3.1$ & $1.94 \pm 1.25$ & $2.08 \pm 3.2$ & 0.345 \\
\hline \multicolumn{5}{|l|}{ FT4 (ng/dL) } \\
\hline Mean \pm SD & $1.1 \pm 02$ & $1.11 \pm 0.23$ & $1.11 \pm 0.20$ & 0.982 \\
\hline \multicolumn{5}{|l|}{ TPOAb (U/mL) } \\
\hline $\mathrm{Ab}+$ & $(9.9 \%) 36 / 363$ & (9.5\%) $4 / 42$ & $(9.9 \%) 32 / 321$ & 0.934 \\
\hline \multicolumn{5}{|c|}{ Thyroid volume (mL) } \\
\hline Mean \pm SD & $12.86 \pm 17.86$ & $12.94 \pm 8.74$ & $12.85 \pm 18.73$ & 0.459 \\
\hline \multicolumn{5}{|c|}{ Urinary iodine $(\mu \mathrm{g} / \mathrm{L})$} \\
\hline Median & $210.0(40-856)$ & $216.1(94-832)$ & $208.1(40-858)$ & 0.497 \\
\hline
\end{tabular}

Values in parentheses represent ranges.

average mean serum TSH value was significantly higher in the studied population when compared with the normal reference group $(1.8 \pm 0.8 \mu \mathrm{U} / \mathrm{mL}, \mathrm{p}=0.02)$ although the biological importance of such a small difference is debatable. When subdivided according to the age ranges, the mean TSH values were as follows: $60-70$ years, $1.66 \pm 1.18 \mu \mathrm{U} / \mathrm{mL}$; 71-80 years, $2.04 \pm 2.78 \mu \mathrm{U} / \mathrm{mL}$; and $81-92$ years, $2.61 \pm$ $5.3 \mu \mathrm{U} / \mathrm{mL}$. There was a positive and significant correlation between the serum TSH levels and increasing age $(\mathrm{p}=0.01)$ (Figure 1). Significant difference in the TSH values was observed among age groups $(\mathrm{p}=0.02)$ (Figure 1) but not between genders $(\mathrm{p}=0.36)$.

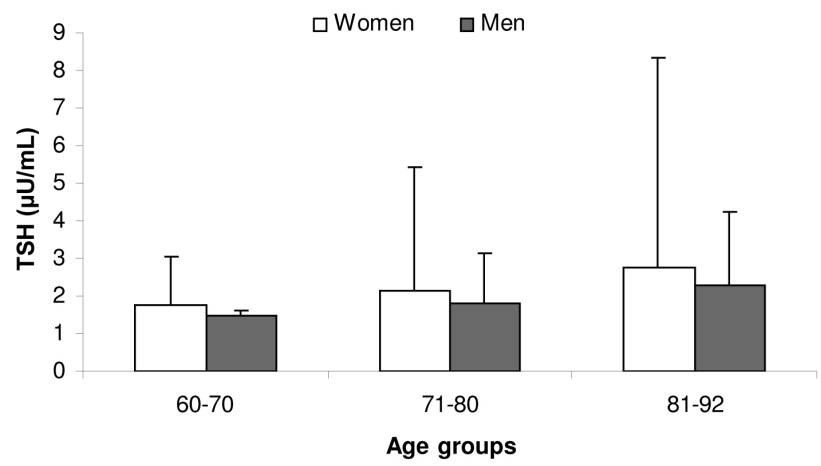

Figure 1 - TSH levels within age groups. Note the increasing TSH values with age in men and women $(\mathrm{p}=<0.02)$

\section{FT4}

The mean serum FT4 level was $1.11 \pm 0.21 \mathrm{ng} / \mathrm{dL}$ (median $1.1 \mathrm{ng} / \mathrm{dL}$, range $0.1-2.4 \mathrm{ng} / \mathrm{dL}$ ) (Table 1). There was no difference in the FT4 levels between men and women (median $1.11 \mathrm{ng} / \mathrm{dL}$, range $0.03-2.35 \mathrm{ng} / \mathrm{dL}$ versus $1.11 \mathrm{ng} /$ $\mathrm{dL}$, range $0.74-1.72 \mathrm{ng} / \mathrm{dL}$, respectively, $\mathrm{p}=0.914)$. The mean serum FT4 levels were significantly lower in the studied population when compared with the normal reference group $(1.17 \pm 0.18 \mathrm{ng} / \mathrm{dL}$, median=1.2 ng/dL, range $0.8-1.9 \mathrm{ng} /$ $\mathrm{dL}, \mathrm{p}=0.001)$.

\section{TPOAb}

Positive TPOAb values were found in 36 patients (9\%), with similar frequencies in women $(9.7 \%, \mathrm{n}=26)$ and men (7.6\%, $\mathrm{n}=10, \mathrm{p}=0.498$ ) (Table 1).

\section{Ultrasonographic abnormalities}

Hypoechogenicity (grades 3 and 4) was present in 67 patients $(16.8 \%)$ and was considered indicative of chronic autoimmune thyroiditis. Fifty-six of the 268 women $(20.9 \%)$ presented with marked hypoechogenicity, compared with 11 out of the 131 men $(8.4 \%, \mathrm{p}<0.001)$. Thyroid cysts were detected in 11 subjects $(2.8 \%$, nine women), single nodules were found in 102 subjects (79 women, 25.6\%), and multiple nodules were found in 34 individuals (8.5\%, 24 women) (Figure 2).

\section{Thyroid volume}

The thyroid volumes of the studied subjects are shown in Table 1. Thyroid enlargement was found in 45 patients 


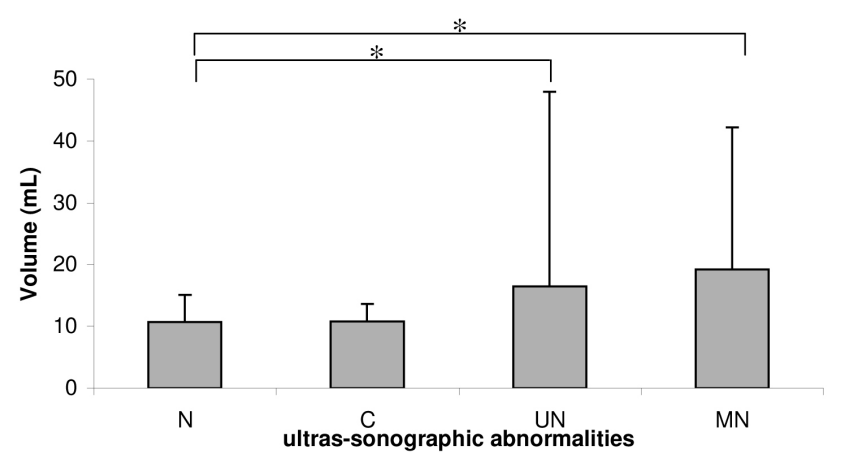

Figure 2 - Thyroid volume compared with different ultrasonographic findings. N: no abnormality; C: cysts; UN: single nodule; and MN: multinodular goiter. Note that patients with thyroid nodules had a significantly increased thyroid volume $(* \mathrm{p}<0.01)$

$(11.3 \%)$, with a significant difference between the mean thyroid volume for women $(13.0 \pm 21.4 \mathrm{~mL}$, range 3.3-320 $\mathrm{mL})$ compared with men $(12.5 \pm 6.0 \mathrm{~mL}$, range $2.7-54.2$ $\mathrm{mL}, \mathrm{p}=0.001$ ). There was no difference in thyroid volume between the normal reference group and the studied cohort $(\mathrm{p}=0.813)$. A significantly increased thyroid volume was seen in the participants with single nodules $(11.4 \mathrm{~mL}$, range $3.9-320 \mathrm{~mL}$ ) and multiple nodules $(12.9 \mathrm{~mL}$, range $4.1-122$ $\mathrm{mL})$ compared with patients without nodules $(10.4 \mathrm{~mL}$, range $2.7-35 \mathrm{~mL}, \mathrm{p}<0.01$ ) (Figure 2).

\section{Urinary and household salt iodine concentrations}

The urinary iodine concentration of the studied population is shown in Figure 3. In 13 of the patients (3.3\%), urinary iodine levels were below $100 \mu \mathrm{g} / \mathrm{L}$, whereas in 116 patients $(30.8 \%)$, the values were above $300 \mu \mathrm{g} / \mathrm{L}$. Overall, the studied population had a median urinary iodine excretion of $210 \mu \mathrm{g} / \mathrm{L}$ (range $40-856 \mu \mathrm{g} / \mathrm{L}$ ). Male subjects presented with a mean urinary iodine concentration that was significantly higher than women $(279.0 \pm 142.0 \mu \mathrm{g} / \mathrm{L}$ versus $243.0 \pm 130.0 \mu \mathrm{g} / \mathrm{L}$, respectively, $\mathrm{p}=0.006$ ) (Figure $3)$. The studied population had a significantly lower median urinary iodine concentration compared with a population of

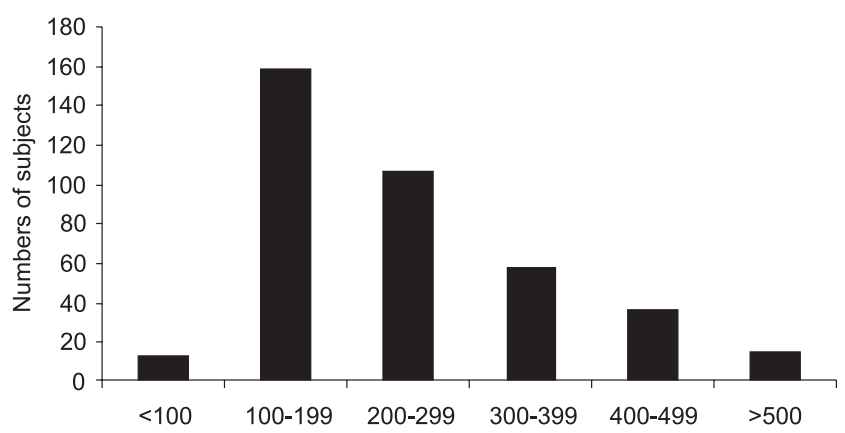

Figure 3 - Distribution of iodine concentration in the studied population. The median urinary excretion was $210 \mu \mathrm{g} / \mathrm{L}$. Note that one-third of the subjects had an excessive iodine excretion $(>300 \mu \mathrm{g} / \mathrm{L})$
1,017 adults from São Paulo. ${ }^{16}$ The median urinary iodine concentration, according to age range quartiles, were as follows: $60-70$ years, $243 \mu \mathrm{g} / \mathrm{L}$ (range $40-856 \mu \mathrm{g} / \mathrm{L}$ ); 71-80 years, $203 \mu \mathrm{g} / \mathrm{L}$, range $84-832 \mu \mathrm{g} / \mathrm{L}$; and $81-92$ years, 203 $\mu \mathrm{g} / \mathrm{L}$, range $100-594 \mu \mathrm{g} / \mathrm{L}$. No significant difference was observed among the age groups $(\mathrm{p}=0.19)$.

The mean iodine content in the 97 household salt samples that were evaluated was $35.6 \pm 8.9 \mathrm{mg} \mathrm{I} / \mathrm{kg}$ (range $23.8-81.2$ $\mathrm{mg} \mathrm{I} / \mathrm{kg}$ ). These values are in accordance with the current legal recommendation.

\section{Relationship between atrial fibrillation (AF), thyroid abnormalities and urinary iodine}

Elderly patients with atrial fibrillation $(n=46)$ were significantly older than those without arrhythmia (mean age $76.6 \pm 6.3$ years versus $72.8 \pm 7.5$ years, $\mathrm{p}=0.001$ ). There was no relationship between thyroid function, thyroid size, gender and urinary iodine concentration between patients with or without atrial fibrillation (Table 1). Three out of 46 patients $(6.5 \%)$ with AF presented with subclinical hyperthyroidism, and five of these patients (10.9\%) had subclinical hypothyroidism.

\section{DISCUSSION}

Thyroid dysfunction in elderly individuals often occurs unnoticed, and methods for accurate detection may be controversial. ${ }^{17}$ Therefore, screening for thyroid nodular disease, hypothyroidism and hyperthyroidism is recommended in older patients ${ }^{18}$. Screening for overt hypoor hyperthyroidism usually reveals patients with subclinical forms of the disease, e.g., subclinical hypothyroidism (elevated serum TSH and normal FT4 levels) and subclinical hyperthyroidism (suppressed serum TSH and normal F T4 levels).

Subclinical thyroid dysfunction has been associated with a range of serious clinical outcomes and increased risk of progression to overt thyroid dysfunction. Environmental factors, such as sustained and elevated levels of nutritional iodine, have been associated with hyperthyroidism in the elderly, a population with increased prevalence of nodular thyroid disease. ${ }^{19}$ Nodular disease, both with the presence of single (cystic or solid) or multiple nodules, may be present in up to $50 \%$ of individuals above the age of 55 years. ${ }^{5}$ Iodine excess is also frequently associated with an increased prevalence of chronic autoimmune thyroid disease, which affects mostly women. ${ }^{20}$

Another feature of increasing age is a decrease in the hypothalamic-pituitary response to low serum FT4 and total T4 levels. Serum TSH levels are lower among the 
elderly compared to younger patients with the same degree of thyroid failure..$^{21}$ A slight increase in serum TSH may indicate hypothyroidism in older adults, compared to younger individuals. This event is also observed among elderly patients with thyroid cancer who need a longer time period to reach sufficiently high TSH values to allow for an effective radioiodine ablation following thyroid hormone withdrawal.

Atrial fibrillation is an important dysrhythmia that represents an independent risk factor for other cardiovascular events and stroke. ${ }^{22}$ Low serum TSH is considered a risk factor for atrial fibrillation in older patients. ${ }^{23}$ More recently, Gammage et al. ${ }^{22}$ found a risk factor between the serum FT4 concentration and atrial fibrillation. Even in euthyroid subjects with normal serum TSH levels, the serum FT4 concentration was independently associated with atrial fibrillation in their study. ${ }^{22}$

In the present study, we studied an elderly population from cardiac outpatient clinics. The majority of these patients had mild hypertension, chronic fatigue, and possibly an early stage of mild cardiac failure; otherwise, these patients were in relatively good health. Among these patients, $11.5 \%$ presented with atrial fibrillation. We compared the thyroid function tests and autoantibodies, thyroid volume and urinary excretion of iodine in both group of patients with and without atrial fibrillation, and we could not find a significant difference between genders, with respect to the serum TSH, serum FT4, TPOAb, thyroid volume or urinary iodine concentration. Thus, we could not associate the presence of atrial fibrillation with thyroid dysfunction in this population.

Serum TSH values increased according to age in both genders. This increase attained statistical significance among age groups (Figure 2) but not between genders. Moreover there was a positive and significant correlation of serum TSH and increasing age. Overall, the serum FT4 concentrations were similar in both genders, but the levels were significantly lower in the elderly when compared with the normal reference group. This observation confirms that the serum FT4 values have a tendency to be lower in the elderly as compared with a normal, younger adult population.

Severe hypoechogenicity, as seen in the ultrasonographic studies of this population, is an excellent method to determine the presence of chronic autoimmune thyroid disease. Indeed, Raber et al. ${ }^{24}$ have found that grades 3 and 4 hypoechogenicity have a higher predictive value for the diagnosis of Hashimoto's thyroiditis when compared with the presence of thyroid autoantibodies (TPOAb). In our study, $17 \%$ of the patients filled the criteria for a marked hypoechoic pattern, but only half of these patients $(9 \%)$ had a positive TPOAb. We may assume that the presence of both hypoechogenicity and TPOAb positivity is compatible with a diagnosis of Hashimoto's thyroiditis in the elderly. However, the presence of an isolated marked hypoechogenicity should be considered as indicative of chronic autoimmune thyroid disease, even in the absence of TPOAbs. One possible explanation for this indication would be a presumably low response of the immunologic system to auto-antigens (or antigens in general) that may be present in elderly patients. ${ }^{25}$ In a study conducted in São Paulo in 1994, a relatively higher prevalence of chronic autoimmune thyroid disease was observed in the elderly population when compared with a normal control population. ${ }^{13}$ As the population in this area experienced a period of five years (1998-2003) of excessive iodine intake due to the heavy addition of potassium iodate to table salt (40-100 ppm), it is possible that this environmental factor could have triggered a higher prevalence of Hashimoto's thyroiditis. As observed in other countries, ${ }^{26,27}$ a sustained and prolonged excessive iodine intake may be linked to the increased prevalence of chronic autoimmune thyroid disease. ${ }^{15}$

Thyroid volume significantly increased with advanced age, probably a result of the presence of single or multinodular thyroid disease. This increase is clearly shown in Figure 2, which shows that patients with multinodular goiter had increased thyroid volumes as compared with the echographically normal glands.

Hyperthyroidism (overt and subclinical) was present in $7.3 \%$ of the patients, an increased prevalence when compared with controls (3.3\%). Excessive production of thyroid hormones may be due to Graves' disease (TPOAb and TRAb positivity) or autonomous nodules in patients with single or multinodular thyroid disease. We did not perform TRAb studies in this cohort, and we assume that the relatively high prevalence of hyperthyroidism may be caused by a combination of high nutritional iodine and the presence of thyroid nodules.

Urinary iodine excretion was above $251 \mu \mathrm{g} / \mathrm{L}$ of urine in about one-third of our patients. Men had a higher iodine excretion than women did. The median urinary iodine was similar among the various age groups. Thus, during the period of the completion of this study (2007), elderly patients had a relatively normal nutritional intake, although it is possible that a higher iodine intake occurred during the five-year period of excessive iodine intake (1998-2003). There was no relationship between the urinary iodine concentrations and the presence of atrial fibrillation.

Overt hypothyroidism was present in $4.3 \%$ of the population, and subclinical hypothyroidism was confirmed in an additional $8.1 \%$. Both prevalences were relatively higher compared with other similar population studies. ${ }^{1-3}$ Most of these patients had evidence of marked hypoechogenicity on 
thyroid ultrasound, positive TPOAb or both. Thus, the results of our study corroborate previous findings of a high prevalence of autoimmune thyroid disease in older individuals.

In conclusion, we have confirmed that thyroid dysfunction is highly prevalent in the elderly who present with both hypo- and hyperthyroidism. Autoimmunity (Hashimoto's thyroiditis) is probably the most common cause for decreased thyroid function and may be more prevalent when environmental iodine is excessive. Atrial fibrillation had no relationship with any of the studied thyroid parameters. Urinary iodine excretion was relatively high in this population without relation to increasing age. The serum TSH value (but not FT4) increased with age. Thyroid nodular disease (either single or multiple nodules) was highly prevalent $(36.8 \%)$, confirming that nodular thyroid disease is common in the elderly. Taking into account all these facts, we suggest that elderly patients should be screened for thyroid dysfunction, particularly in an environment with relatively high iodine intake.

\section{ACKNOWLEDGEMENTS}

We gratefully acknowledged Adolfo Lutz Institute, a Public Health Laboratory in São Paulo (Brazil) for urinary iodine studies, and Prof. Celia Colli, Dept of Food and Experimental Nutrition, University of São Paulo, Pharmaceutical Sciences School, São Paulo, Brazil, who analyzed salt iodine content.

\section{REFERENCES}

1. Tunbridge WM, Evered DC, Hall R, Appleton D, Brewis M, Clark F, et al. The spectrum of thyroid disease in a community: the Wickham survey. Clin Endocrinol. 1977;7:481-93.

2. Canaris GJ, Manowitz NR, Mayor G, Ridgway ECl. The Colorado thyroid disease prevalence study. Arch Intern Med. 2000;160:526-34

3. Hollowell JG, Staehling NW, Flanders WD, Hannon WH, Gunter EW, Spencer CA, et al. Serum TSH, $\mathrm{T}_{4}$, and thyroid antibodies in the United States population (1988 to 1994). J Clin Endocrinol Metab. 2002;87:48999.

4. Weissel M. Disturbances of thyroid function in the elderly. Wien Klin Wochenschr. 2006;118:16-20.

5. Mariotti S, Franceschi C, Cossarizza A, Pinchera A. The aging thyroid. Endocr Rev. 1995;16:686-715.

6. Laurberg P, Bülow Pedersen I, Knudsen N, Ovesen L, Andersen S. Environmental iodine intake affects the type of nonmalignant thyroid disease. Thyroid. 2001;11:457-69.

7. Laurberg P, Pedersen KM, Vestergaard H, Sigurdsson G. High incidence of multinodular toxic goiter in the elderly population in a low iodine intake area vs. high incidence of Graves' disease in the young in a high iodine intake area: comparative surveys of thyrotoxicosis epidemiology in East-Jutland Denmark and Iceland. J Intern Med. 1991;229:41520 .

8. Cavaliere R, Antonangeli L, Vitti P, Pinchera A, Aghini-Lombardi F. The aging thyroid in a mild to moderate iodine deficient area of Italy. J Endocrinol Invest. 2002;25:66-8.

9. Diez JJ. Goiter in adult patients aged 55 years and older: Etiology and clinical features in 634 patients. J Geront. 2005;60:920-3.

10. Bagchi N, Brown TR, Parish RF. Thyroid dysfunction in adults over age 55 years. A study in an urban US community. Arch Intern Med. 1990;150:785-7.
11. Chiovato L, Mariotti S, Pinchera A. Thyroid diseases in the elderly. Baillieres Clin Endocrinol Metab 1997;11:251-70.

12. Duarte GC, Tomimori EK, Bariolli RA, Ferreira JE, Catarino RM, Camargo RYA, et al. Avaliação ultra-sonográfica da tireóide e determinação da ioduria em escolares de diferentes regiões do estado de São Paulo. Arq Bras Endocr Metab. 2004;49:842-8.

13. Tomimori EK, Pedrinola F, Cavaliere H, Knobel M, Medeiros-Neto G. Prevalence of incidental thyroid disease in a relatively low iodine intake area. Thyroid.1995;5:273-6.

14. Mazziotti G, Sorvillo F, Iorio S, Carbone A, Romeo A, Piscopo M, et al. Grey-scale analysis allows a quantitative evaluation of thyroid echogenicity in the patients with Hashimoto's thyroiditis. Clin Endocrinol. 2003;59:223-9.

15. Als C, Helbling A, Peter K, Haldimann M, Zimmerli B, Gerber H. Urinary iodine concentration follows a circadian rhythm: a study with 3023 spot urine samples in adults and children. J Clin Endocrinol Metab. 2000;85:1367-9.

16. Camargo YA, Tomimori EK, Neves SC, Rubio IGS, Galrão AL, Knobel $\mathrm{M}$, et al. Thyroid and the environment: exposure to excessive nutritional iodine increases the prevalence of thyroid disorders in São Paulo, Brazil. Eur J Endocrinol. 2008;159:293-9.

17. Camargo RY, Pellanda L, Porta V, Maciel, P, Furquim A, Schaan B. Preoperative assessment of thyroid nodules: role of ultrasonography and fine needle aspiration biopsy followed by cytology. Clinics. 2007;62:411-8

18. Gussekloo J, van Exel E, de Craen AJM, Meinders AE, Frolich M \& Westendorp RGJ. Thyroid status, disability and cognitive function, and survival in old age. JAMA. 2004;292:2591-9.

19. Stanbury JB, Ermans AE, Bourdoux P, Todd C, Oken E, Tonglet R, et al. Iodine-induced hyperthyroidism: occurrence and epidemiology. Thyroid. 1998;8:83-100. 
20. Weetman AP. Autoimmune thyroid disease: propagation and progression. Eur J Endocrinol. 2003;148:1-9.

21. Carlé A, Laurberg P, Pedersen IB, Perrild H, Ovesen L, Rasmussen $\mathrm{LB}$, et al. Age modifies the pituitary TSH response to thyroid failure accompanied by a high prevalence of goiter, mainly in areas of low iodine intake. Thyroid. 2007;7:139-44.

22. Gammage MD, Parle JV, Holder RL, Roberts LM, Hobbs FDR, Wilson $\mathrm{S}$, et al. Association between serum free thyroxine concentration and atrial fibrillation. Arch Intern Med. 2007;167:928-34.

23. Sawin CT, Geller A, Wolf PA, Belanger AJ, Baker E, Bacharach P, et al. Low serum thyrotropin concentrations as a risk factor for atrial fibrillation in older persons. N Engl J Med. 1994;331:1249-52.
24. Raber W GA, Nowotny P, Vierhepper H. Thyroid ultrasound versus antithyroid peroxidase antibody determination: a cohort study of four hundred fifty-one subjects. Thyroid. 2002;12:725-31.

25. Weetman AP, McGregor MA. Autoimmune thyroid disease: further developments in our understanding. Endocr Reviews.1994;15:788-829.

26. Zois C, Stavrou I, Kalogera C, Svarna E, Dimoliatis I, Seferiadis K, et al. High prevalence of autoimmune thyroiditis in schoolchildren after elimination of iodine deficiency in northwestern Greece. Thyroid. 2003;13:485-9.

27 Teng W SZ, Teng X, Guan H, Li Y, Teng D, Jin Y, et al. Effect of iodine intake on thyroid diseases in China. N Engl J Med. 2006;354:278393. 